\title{
COMPARATIVE EVALUATION OF PROTECTIVE POTENTIAL OF TOOTHMIN AND NOVAMIN CONTAINING TOOTHPASTES ON ENAMEL SURFACE UNDER CONFOCAL MICROSCOPE: AN IN VITRO STUDY
}

\author{
Anurag Aggarwal ${ }^{1}$, Shalu Krishan Gupta ${ }^{2}$, Kanwarpreet Singh ${ }^{3}$, Simran Pal Singh Bindra \\ ${ }^{1}$ Reader, Department of Conservative Dentistry and Endodontics, National Dental College, Punjab, India \\ ${ }^{2}$ Professor and HOD, Department of Conservative Dentistry and Endodontics, National Dental College, Punjab, India \\ ${ }^{3}$ PG Student, Department of Conservative Dentistry and Endodontics, National Dental College, Punjab, India \\ ${ }^{4}$ PG Student, Bhojia Dental College, Himachal Pradesh, India
}

\begin{abstract}
\begin{tabular}{l|l}
\hline ABSTRACT \\
$\begin{array}{l}\text { Aim: To evaluate the protective potential of calcium sucrose phosphate and novamin containing toothpaste } \\
\text { on enamel surface. Settings and Design: In vitro- study. Materials and Methods: This study consisted of } 30 \\
\text { samples embedded in orthodontic resin with either buccal or lingual surface exposed. The samples were } \\
\text { assigned to either calcium sucrose phosphate containing paste; novamine toothpaste; or control group. The } \\
\text { groups were then subjected to cycling in a demineralizing solution and a remineralizing solution. Groups II } \\
\text { and III received prior application of calcium sucrose phosphate paste and novamine toothpaste respectively } \\
\text { followed by cycling in a demineralizing solution and a remineralizing solution. Following } 14 \text { days of cycling, } \\
\text { the samples were sectioned and examined using confocal microscopy. The depths of lesions were evaluated. } \\
\text { Statistical Analysis: Image Proplus software was used to analyze the images. The values were statistically } \\
\text { evaluated using one - way ANOVA and Scheffe's Test. Results and Conclusion: Within the limitations of } \\
\text { study it was concluded that enamel surfaces treated with calcium sucrose phosphate paste exhibited the least } \\
\text { lesion depths followed by enamel surfaces treated with the novamin tooth paste and control group } \\
\text { respectively. }\end{array}$
\end{tabular}
\end{abstract}
Keywords: Caries, Calcium-sucrose Phosphate, Novamin.

Corresponding Author:

Kanwarpreet Singh

E-mail: dr.kanwar@yahoo.com

Received: $25^{\text {th }}$ April 2016

Accepted: $2^{\text {nd }}$ August 2016

Online: $11^{\text {th }}$ September 2016

\section{INTRODUCTION}

Dental caries is an infectious microbiologic disease of the teeth that results in localized dissolution and destruction of the calcified tissues. The largest increase in prevalence of caries has been associated with dietary changes. The largest increase in prevalence of caries has been associated with dietary changes. ${ }^{1}$ Caries process is dependent upon interaction of protective and pathologic factors in saliva and plaque biofilm as well as the balance between cariogenic and noncariogenic microbial populations that reside in saliva. High fluoride strategy cannot be followed in most of instances to avoid potential for adverse effects due to overexposure to fluoride.

Therefore, there is great scope of new agents that can be used with fluoride to enhance anti-caries activity. ${ }^{2}$ Toothmin tooth cream, a newly introduced remineralizing agent is based on Anticay Technology. This unique technology has been commersialized by Biodental Remin, an Australia based biotechnology 
company. ${ }^{3}$ Novamin is the trade name for calcium sodium phopshosilicate bioactive glass that has been developed for use in oral health care. ${ }^{4}$ This article will focus on the mechanisms of action of both these agents and present the results from an in vitro study that demonstrates the potential of these materials in areas of caries prevention.

\section{AIMS AND OBJECTIVE}

- To determine whether enamel samples treated with toothmin and novamin containing paste can resist acidic challenge in vitro when measured with confocal microscopy.

- To determine whether there is significant difference in lesion depth between untreated enamel surfaces and enamel surfaces treated with toothmin and novamin.

\section{MATERIALS AND METHODS}

Thirty extracted human premolars without enamel defects or decalcification were used in this study. Roots were sectioned at the cementoenamel junction and crowns were sectioned into buccal and lingual halves using high speed water-cooled hand piece and carborundum disc. The crowns were placed in a glass container with deionized water. Tooth crown samples were embedded in orthodontic acrylic with the buccal or lingual surface exposed. A $2 \times 2 \mathrm{~mm}$ window of exposed enamel was created in middle of the sample surface by applying a uniform coat of nail varnish around it. Each mounted specimen was assigned to one of the three different experimental groups and it was stored in deionized water until further use.

Demineralizing solution used was:

- $1 \mathrm{mM}$ (milliMolar) CaCl2 (Calcium chloride)

- $2.2 \mathrm{mMNaH} 2 \mathrm{PO} 4$ (Monosodium phosphate)

- $50 \mathrm{mMC} 2 \mathrm{H} 402$ (Acetic acid)

Remineralizing solution used was:

- 20 mM HEPES (4-(2-hydroxyethyl)-1piperazineethanesulfonic acid )

- $1.5 \mathrm{mMCa} 2+$ as $\mathrm{CaCl} 2$ (Calcium chloride)
- $0.9 \mathrm{mM}$ phosphate as KH2PO4 (Monopotassium phosphate)

- 1 ppm Fluoride as NaF (Sodium Fluoride)

\section{TREATMENT GROUPS}

- Teeth in group I were placed in a demineralising solution with $\mathrm{pH} 4.46$ for period of 8 hours and then removed and placed in artificial saliva for 1 hour. After 1 hour, the teeth were placed in a remineralizing solution with $\mathrm{pH} 7.00$ for the balance of 24 hours (15 hours). This cycling continued for 14 days.

- Novamine tooth paste was applied to exposed enamel surface of teeth in group III with a rubber glove and allowed to sit for $5 \mathrm{~min}$. The specimens in this group were further treated similar to group I.

- Toothmin was applied to exposed enamel surface of teeth in group II with rubber glove, according to the manufacturer's directions, and allowed to sit for a period of $5 \mathrm{~min}$. The specimens in this group were further treated similar to group I.

Carborundum disc was used to section the samples in a buccolingual direction to obtain samples of $\sim 200$ $\mu \mathrm{m}$ thickness. $0.1 \mathrm{mM}$ of rhodamine $\mathrm{B}$ solution was prepared by adding $23.95 \mathrm{mg}$ of rhodamine B dye to $500 \mathrm{ml}$ of deionized water.

The sectioned specimens were stored in $0.1 \mathrm{mM}$ rhodamine $\mathrm{B}$ for $24 \mathrm{~h}$ and then placed in deionized water until further use.

Rhodamine B from the solution incorporates in demineralized tooth structure and does not penetrate sound tooth structure or orthodontic resin.

\section{USE OF CONFOCAL MICROSCOPY}

A confocal laser scanning microscope was used at 10x magnification to view the images. HeNe $543 \mathrm{~nm}$ wavelength laser source was used with a rhodamine filter to excite rhodamine B dye. The images were analyzed using Image proplus software (Figure 1). One-way ANOVA and Scheffe's test were used to 
analyze the data. Significance was established at $\mathrm{P}<0.05$.

\section{RESULTS}

The mean lesion depth observed in the control group was $55 \mu \mathrm{m}$.

The mean lesion depth observed in the toothmin tooth paste-treated group was $21.88 \mu \mathrm{m}$.

The mean lesion depth observed in novamine tooth paste-treated group was $35 \mu \mathrm{m}$ (Graph I).

\section{DISCUSSION}
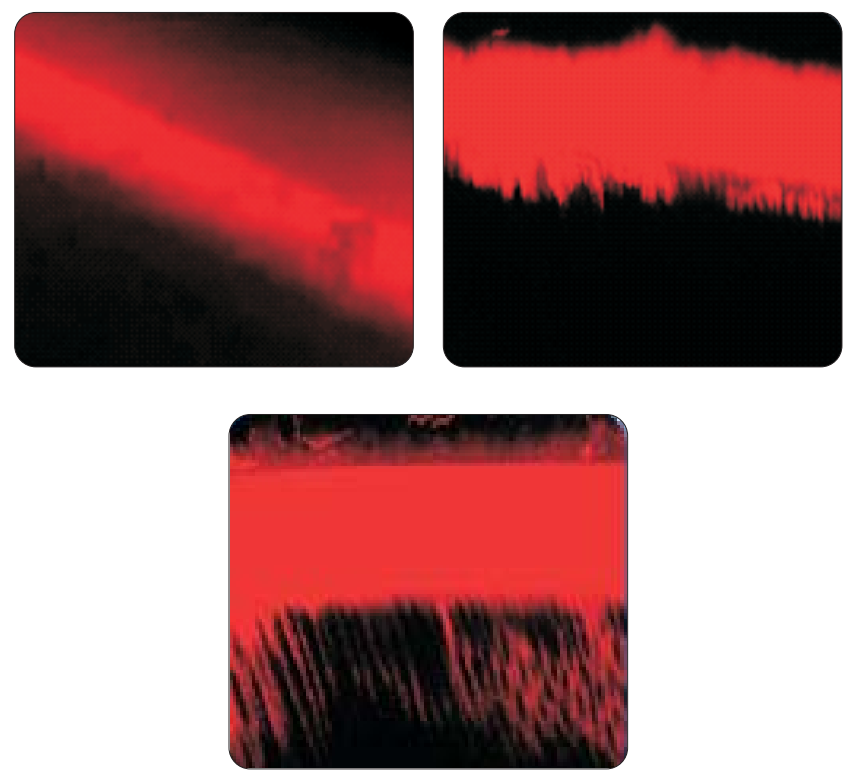

Figure 1: Confocal microscope images were analyzed using Image proplus software

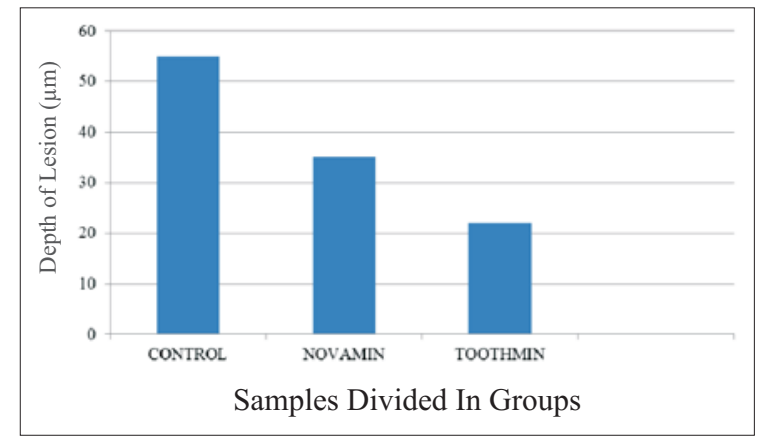

Graph 1: Graph showing mean depth of lesion in various groups
Calcium sodium phosphosilicate is an inorganic compound that reacts in aqueous environments to release calcium, sodium, and phosphate ions over time. Originally developed as a bone regenerative material, this compound has been shown to be effective at physically occluding dentinal tubules through development of a hydroxyapatite-like mineral layer (Andersson and Kangasniemi, 1991; Hench and Andersson, 1993). ${ }^{4,5}$ Clinical evaluations of NovaMin for the treatment of dentin hypersensitivity have shown statistically significant and clinically positive results (unpublished data from IRB-approved clinical trial at the University of Maryland, 1998; Du et al., 2008). The significant clinical treatment of hypersensitivity through formation of crystalline apatite led researchers to hypothesize that NovaMin could be useful in remineralization and prevention of demineralization of tooth structures, especially dentin.

While it is clear that commercially available fluoride dentifrices (1000-1500 ppm) have been very successful in reducing the incidence of juvenile coronal caries, it is also clear that root caries and erosion lesions are increasing at a significant rate (Fejerskov et al., 1993; Lussi and Schaffner, 2000). ${ }^{7}$ Use of 5000-ppm fluoride compositions appears to be better at controlling root caries than standard fluoride compositions, although use of these products is not without some controversy (Lynch and Baysan, 2001). ${ }^{8}$ Since fluoride requires a source of calcium to be effective in remineralization, and salivary insufficiency is a common issue in persons with root caries, an additional source of calcium, in combination with fluoride, could be beneficial in the treatment of root caries. Standard in vitro models have been established to predict the clinical efficacy of active ingredients in oral health care products.

The results of in vitro study presented here demonstrate that NovaMin, can enhance remineralization of enamel and dentin lesions, as well as prevent demineralization from acid challenges. In situ results of repair of surface lesions and abrasions with NovaMin 
further demonstrate the mechanisms of action of the material and suggest potential of this material to repair tooth structures (both dentin and enamel). ${ }^{9}$ If this technology is to be fully accepted, it is necessary to demonstrate the efficacy of calcium sodium phosphosilicate (NovaMin), both alone and in combination with fluoride, in prospective, randomized clinical trials, several of which are currently in progress. ${ }^{10}$

Toothmin tooth cream is a newly introduced remineralizing agent that is based on Anticay Technology. ${ }^{3}$ This unique technology has been commercialised by Biodental Remin, an Australia based Biotechnology Company. Anticay is a mixture of calcium sucrose phosphates and inorganic calcium phosphates consisting of $10-12 \%$ calcium and $8-10 \%$ phosphorous by weight. Calcium sucrose phosphate decreases tooth enamel demineralization, inhibits plaque formation and promotes enamel remineralization. Its effective remineralizing action is because of its solubility in water providing high concentrations of free calcium and phosphate ions several times higher than normally present in saliva. ${ }^{10}$ Anticay also acts as a complement to fluoride. ${ }^{12}$

\section{CONCLUSION}

According to our knowledge, this is the first study comparing remineralizing potential of Novamin versus Toothmin tooth cream. Our study has some limitations. First it is an in vitro study. Remineralization in the oral cavity is a complex procedure involving a change in $\mathrm{pH}$ and replenishment of calcium and phosphate elements. This may not be achieved in the in vitro conditions. We recommend further studies using these products in vivo conditions. Secondly, scanning electron microscopy of enamel surface might add more value to the results.

\section{REFERENCES}

1. Padmini Somasundaram, Vimala N, Lalita Gauri Mandk. Protective potential of casein phosphopeptide amorphous calcium phosphate containing paste. J Conserv Dent 2013;16; $152-6$.

2. Roberts AJ. Role of models in assessing new agents for caries prevention - Non-fluoride systems. Adv Dent Res 1995; 9:304-11.

3. Craig GG. The use of a calcium sucrose phosphates-calcium orthophosphate complex as a cariostatic agent. Br Dent J 1975; 138:25-8.

4. Andersson $\mathrm{OH}$, Kangasniemi I. Calcium phosphate formation at the surface of bioactive glass in vitro. J Biomed Mater Res 1991; 25: 1019-1030.

5. Hench LL, Andersson O. Bioactive glasses. In: Introduction to bioceramics. Singapore: World Scientific,1993; 45-47.

6. Du MQ, Bian Z, Jiang H, Greenspan DC, Burwell AK, Zhong JP. Clinical evaluation of a dentifrice containing calcium sodium phosphosilicate (NovaMin) for the treatment of dentin hypersensitivity. Am J Dent 2008;21:210-214.

7. Featherstone JDB, Lussi A. Understanding the chemistry of dental erosion. Monogr Oral Sci 2006;20: 66-76.

8. Lynch E, Baysan A. Reversal of primary root caries using a dentifrice with a high fluoride content. Caries Res 2001;35: 60-64.

9. Lussi A, Schaffner M. Progression of and risk factors for dental erosion and wedge-shaped defects over a 6 -year period. Caries Res 2000;334:182-187.

10. Silverstone LM. Structural alterations of human dental enamel during incipient carious lesion development. In: Proceedings of Symposium on Incipient Caries of Enamel . Rowe N, editor. Ann Arbor, MI: University of Michigan School of Dentistry 1977;3-42.

11. Rogerson MJ. The role of a calcium sucrose phosphatecalcium orthophosphate complex in the reduction of dental caries. Aust Dent J 1973; 18:160-6.

\section{Source of Support: Nil, Conflict of Interest: None Declared}

